\title{
DAP1 high expression increases risk of lymph node metastases in squamous cell carcinoma of the oral cavity
}

\author{
M. Santos ${ }^{1}$, L.L. Maia ${ }^{2}$, C.V.M. Silva ${ }^{2}$, G.T. Peterle², A.M.C. Mercante ${ }^{3}$, \\ F.D. Nunes ${ }^{4}$, M.B. Carvalho ${ }^{3}$, E.H. Tajara ${ }^{5}$, I.D. Louro ${ }^{2}$ and \\ A.M.A. Silva-Conforti2 ${ }^{2,6}$ \\ ${ }^{1}$ Escola Multicampi de Ciências Médicas, \\ Universidade Federal do Rio Grande do Norte, Caicó, RN, Brasil \\ ${ }^{2}$ Programa de Pós-Graduação em Biotecnologia, \\ Universidade Federal do Espírito Santo, Vitória, ES, Brasil \\ ${ }^{3}$ Laboratório de Biologia Molecular, Hospital Heliópolis, São Paulo, SP, Brasil \\ ${ }^{4}$ Faculdade de Odontologia, Universidade de São Paulo, São Paulo, SP, Brasil \\ ${ }^{5}$ Departamento de Biologia Molecular, Faculdade de Medicina, \\ São José do Rio Preto, SP, Brasil \\ ${ }^{6}$ Departamento de Biologia, Universidade Federal do Espírito Santo, Alegre, \\ ES, Brasil \\ Corresponding author: A.M.A. Silva-Conforti \\ E-mail: adriana.biomol@gmail.com \\ Genet. Mol. Res. 14 (3): 10515-10523 (2015) \\ Received February 3, 2015 \\ Accepted June 8, 2015 \\ Published September 8, 2015 \\ DOI http://dx.doi.org/10.4238/2015.September.8.13
}

\begin{abstract}
Death-associated protein 1 (DAP1) is a member of the DAP family. Its expression is associated with cell growth and normal death of the neoplastic cells, regulated by the mammalian target of the rapamycin protein. Activated DAP1 negatively regulates autophagy, which has been associated with the development and progression of several diseases, such as cancer, and with prognosis and survival of diverse tumor types. Therefore, in this study we analyzed DAP1
\end{abstract}


expression in 54 oral squamous cell carcinoma tumor samples and in 20 non-tumoral margins by immunohistochemistry. The results showed that DAP1 is more frequently expressed in tumor tissues compared with marginal non-tumoral cells. Additionally, high DAP1 expression is associated with a 4-fold increase in the risk of lymph node metastases. Our results suggest that the DAP1 protein can be used as a potential marker of lymph node metastases predisposition, helping define the best therapy for each patient to minimize risk of developing metastases.

Key words: DAP1 expression; Lymph node; Prognostic marker; Oral cancer

\section{INTRODUCTION}

Head and neck squamous cell carcinoma (SCC) is a significant cause of morbidity and mortality worldwide, with approximately 780,000 cases and 391,000 deaths reported every year (Perez-Ordoñez et al., 2006; Heroui et al., 2013).

When diagnosed during the initial stages, this disease has a disease-free life expectancy varying from 60 to $90 \%$. However, when the disease is diagnosed at advanced stages, only $50 \%$ of the tumors are operable with a survival rate of $40-50 \%$. Non-operable cases show an even worse prognosis, with survival varying from 10 to $40 \%$ over 5 years (AJCC, 2002; Jemal et al., 2007; Adrien et al., 2014).

Molecular tests can provide a better understanding of tumor behavior and improve prognostic predictions, increasing life expectancy in patients with oral SCC to approximately $80 \%$ (Forastiere et al., 2001; McCarthy et al., 2004).

Disease aggressiveness is directly related to tumor cell adaptation to harsh microenvironment conditions, and the ability to metastasize (Mawrin et al., 2006; Stadler et al., 2008).

Several proteins have been investigated for their possible association with carcinogenesis and prognosis in SCC. Among these, the death-associated protein (DAP) family is particularly interesting. The DAP family includes DAP1, DAP2 (DAP kinase), DAP3, DAP4, and DAP5, which share pro-apoptotic domains. These proteins are related to cell death mediated by tumor necrosis factor alpha and the Fas ligand (Cohen et al., 1999; Jia et al., 2014; Wazir et al., 2014).

DAP1 protein expression is related to cell growth and death regulation, including in tumor cells, through negative regulation of autophagy (Jia et al., 2014). DAP1 is regulated by the mammalian target of rapamycin (mTOR), being functionally silenced in cells present in nutrientrich environments by the inhibitory phosphorylation of mTOR on amino acid residues Ser3 and Ser51. During nutrient starvation, mTOR is inactivated, resulting in a rapid reduction of DAP1 phosphorylation, causing its activation and promoting inhibition of autophagy (Koren et al., 2010).

Autophagy is essential for cellular homeostasis, as dysregulation of this process has been associated with several diseases, such as cancer, autoimmune and cardiovascular diseases, neurodegeneration, and cell senescence (Kondo et al., 2005; Koren et al., 2010).

Autophagy dysregulation has been associated with breast (Wazir et al., 2014) and colorectal cancer (Jia et al., 2014), suggesting its role as a molecular marker of tumor suppression, survival, and disease prognosis. For these reasons, autophagy and DAP1 have become important 
targets for new cancer therapies (Jia et al., 2014).

In a previous study, our group investigated the expression of DAP1 in more aggressive oral tumors (tumors with premature metastasis; $\mathrm{T} 1 / \mathrm{T} 2, \mathrm{~N}+$ ), as well as less aggressive tumors (advanced tumors without metastasis; T3/T4, N0) (Severino et al., 2008), through microarray experiments.

Based on these results, the present study aimed to evaluate the association of DAP1 with oral SCC development and prognosis.

\section{MATERIAL AND METHODS}

\section{Ethics}

This study was approved by the Committee of Ethics in Research of the Heliópolis Hospital (No. 386) and written informed consent was obtained from all patients enrolled.

\section{Samples}

Samples were collected by the Head and Neck Genome Project (GENCAPO), a collaborative consortium created in 2002 with more than 50 researchers from nine institutions in São Paulo State, Brazil, with the aim of developing clinical, genetic, and epidemiological analysis of head and neck SCC. For this study, samples from 54 tumors and 20 non-tumoral surgical margins were obtained and used for immunohistochemical analysis of the DAP1 protein. The samples were taken from a total of 54 patients with oral SCC that were receiving surgical treatment at the Head and Neck Surgery Department of Heliópolis Hospital, São Paulo, Brazil, between January 2002 and December 2008. The clinical follow-up lasted for at least 24 months after surgery. Previous surgical or chemotherapeutic treatment, distant metastasis, cervical lymph nodes, and positive surgical margins were exclusion criteria. Histopathological slides were reviewed by a senior pathologist to confirm the diagnosis and select appropriate areas for immunohistochemical analysis. Tumors were classified according to the TNM system (7th edn; UICC, 2009).

Among the individuals analyzed, the mean age was $54.6 \pm 10.1$ years, $47(87.0 \%)$ being men and $7(13.0 \%)$ women (Table 1). With regards to the anatomical tumor sub-sites, 19 $(35.2 \%)$ were on the tongue, $11(20.4 \%)$ were on the gum, $19(35.2 \%)$ were on the floor of the mouth, and $5(9.3 \%)$ were in the retromolar area.

\section{Tissue microarray}

Tissue microarrays were made using buffered, formalin-fixed, paraffin-embedded tissue sections from 54 primary oral and oropharyngeal SCC patients treated at the Head and Neck Surgery Department of Heliópolis Hospital, São Paulo, SP. The sections were used for immunohistochemistry analysis. Histological characterization of all samples was carried out by hematoxylin and eosin staining, followed by immunohistochemistry analysis of tissue microarrays. Two 1-mm cylinders were used to represent each sample in the tissue microarrays slide (Beecher Instruments ${ }^{\circledR}$, Silver Spring, MD, USA). Tumor histological characteristics were evaluated by regular microscopy. 


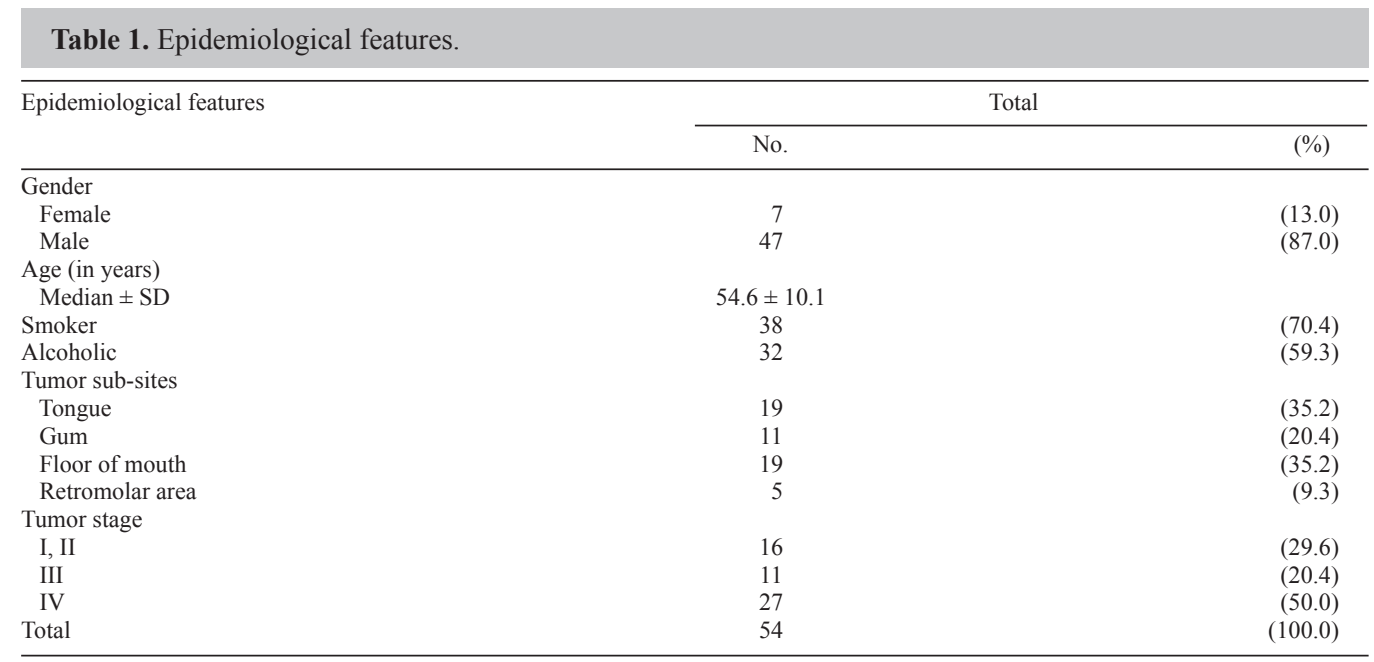

\section{Immunohistochemistry}

Anti-DAP1 monoclonal antibody $\left(\mathrm{Abcam}^{\circledR}\right)$ was used in the IHC reaction, at a 1:50 dilution (Rimm et al., 2001; Hedvat et al., 2002; Hsu et al., 2002). Positive and negative controls (absence of primary antibody) were used for reaction quality control. Sample scoring was performed by semi-quantitative microscopic analysis, considering the number of stained tumor cells and signal intensity. Two spots were evaluated for each sample and a mean score was calculated. Considering the percentage of DAP1 immune-positive tumor cells, a score of 1 was given when $\leq 10 \%$ of cells were positive; 2 when $11-50 \%$ of cells were positive, and 3 when $>50 \%$ of cells were positive. The signal intensity was scored as weak 1), moderate 2), and strong 3). Both scores were multiplied (dos Santos et al., 2012) and the resulting score was used to categorize DAP1 expression as negative (0), positive low (1-4), and positive high ( $\geq 4)$.

\section{Statistical analysis}

Chi-square and Fisher exact tests were used for association analysis and confirmation was obtained by the Lilliefors test (results were considered to be significant when $\mathrm{P}<0.05$ ). Multivariate logistic regression was used to calculate odds ratios and $95 \%$ confidence intervals. Survival time was considered to be the number of months between surgery and death for each patient, or the last appointment in cases where the patient was still alive. To calculate local disease-free survival, the time endpoint was the date of local disease relapse. The KaplanMeier model was used for survival analysis, using the Wilcoxon P value and Cox proportional hazards to adjust $P$ values and obtain hazard ratios. Statistical calculations were performed using the Epi-Info ${ }^{\circledR}$ v3.4.3, 2007 and StatSoft Statistica ${ }^{\circledR}$ v7.0.61.0 softwares.

\section{RESULTS}

DAP1 expression was examined in 54 tumors, of which 51 were positive $(94.4 \%)$ 
and only three were negative (5.6\%). In non-tumoral surgical margins, DAP1 expression was positive in six (30.0\%) and negative in $14(70.0 \%)$. DAP1 expression was different in tumors and non-tumoral samples $(\mathrm{P}<0.001$; Table 2$)$.

\begin{tabular}{|c|c|c|c|c|c|}
\hline \multirow[t]{2}{*}{ DAP1 expression } & \multicolumn{2}{|c|}{ Tumor } & \multicolumn{2}{|c|}{ Surgical margin } & \multirow[t]{2}{*}{$P$ value } \\
\hline & No. & $(\%)$ & No. & $(\%)$ & \\
\hline Negative & 3 & $(5.6)$ & 14 & $(70.0)$ & $<0.001$ \\
\hline Positive & 51 & (94.4) & 6 & $(30.0)$ & \\
\hline Low & 17 & (31.5) & 2 & $(10.0)$ & 0.661 \\
\hline High & 34 & (63.0) & 4 & $(20.0)$ & \\
\hline Total & 54 & $(100.0)$ & 20 & $(100.0)$ & \\
\hline
\end{tabular}

DAP1 expression did not show a significant association with tumor characteristics such as size $(\mathrm{P}=0.699)$, differentiation grade $(\mathrm{P}=0.342)$, lymphatic invasion $(\mathrm{P}=0.192)$, and perineural invasion $(\mathrm{P}=0.842)$, but the expression was significantly associated with lymph node status $(\mathrm{P}=0.029$; Table 3$)$. Multivariate analysis showed that high DAP1 expression was an independent marker for lymph node metastases $(\mathrm{OR}=4.27,95 \% \mathrm{CI}=1.10-16.59$; Table 4).

\begin{tabular}{|c|c|c|c|c|c|c|c|}
\hline \multirow[t]{3}{*}{ Features } & \multirow{2}{*}{\multicolumn{2}{|c|}{ Total }} & \multicolumn{5}{|c|}{ DAP1 expression } \\
\hline & & & \multicolumn{2}{|c|}{ Low } & \multicolumn{2}{|c|}{ High } & \multirow[t]{2}{*}{ P valuc } \\
\hline & No. & $(\%)$ & No. & $(\%)$ & No. & $(\%)$ & \\
\hline \multicolumn{8}{|l|}{ Tumor size $(T)^{\mathrm{a}}$} \\
\hline $\mathrm{pT} 1, \mathrm{pT} 2$ & 21 & $(41.2)$ & 7 & $(41.2)$ & 14 & $(41.2)$ & 0.699 \\
\hline pT3 & 9 & (17.6) & 4 & $(23.5)$ & 5 & (14.7) & \\
\hline pT4 & 21 & $(41.2)$ & 6 & $(35.3)$ & 15 & $(44.1)$ & \\
\hline \multicolumn{8}{|c|}{ Lymph node metastases $(\mathrm{N})^{\mathrm{a}}$} \\
\hline Absent & 25 & $(49.0)$ & 12 & $(70.6)$ & 13 & $(38.2)$ & 0.029 \\
\hline Present & 26 & $(51.0)$ & 5 & $(29.4)$ & 21 & $(61.8)$ & \\
\hline \multicolumn{8}{|l|}{ Differentiation } \\
\hline Good & 21 & $(41.2)$ & 9 & $(52.9)$ & 12 & $(35.3)$ & 0.342 \\
\hline Moderate & 28 & $(54.9)$ & 8 & $(47.1)$ & 20 & $(58.8)$ & \\
\hline Poor & 2 & (3.9) & 0 & $(0.0)$ & 2 & $(5.9)$ & \\
\hline \multicolumn{8}{|c|}{ Lymphatic invasion } \\
\hline Absent & 15 & $(29.4)$ & 7 & $(41.2)$ & 8 & $(23.5)$ & 0.192 \\
\hline Present & 36 & (70.6) & 10 & $(58.8)$ & 26 & (76.5) & \\
\hline \multicolumn{8}{|c|}{ Perineural invasion } \\
\hline Absent & 23 & $(45.1)$ & 8 & $(47.1)$ & 15 & $(44.1)$ & 0.842 \\
\hline Present & 28 & (54.9) & 9 & $(52.9)$ & 19 & (55.9) & \\
\hline \multicolumn{8}{|l|}{ Disease relapse } \\
\hline No & 17 & $(33.3)$ & 3 & $(17.6)$ & 14 & $(41.2)$ & 0.083 \\
\hline Yes & 34 & $(66.7)$ & 14 & (82.4) & 20 & (58.8) & \\
\hline \multicolumn{8}{|c|}{ Local disease relapse } \\
\hline No & 29 & $(56.9)$ & 6 & (35.3) & 23 & (67.6) & 0.027 \\
\hline Yes & 22 & $(43.1)$ & 11 & (64.7) & 11 & (32.4) & \\
\hline \multicolumn{8}{|c|}{ Disease-specific death } \\
\hline No & 20 & $(39.2)$ & 6 & $(35.3)$ & 14 & $(41.2)$ & 0.747 \\
\hline Yes & 26 & $(51.0)$ & 9 & $(52.9)$ & 17 & $(50.0)$ & \\
\hline Not available ${ }^{\mathrm{b}}$ & 5 & $(9.8)$ & 2 & (11.8) & 3 & $(8.8)$ & \\
\hline Total & 51 & $(100.0)$ & 17 & (33.3) & 34 & (66.7) & \\
\hline
\end{tabular}

${ }^{a}$ TNM classification 7 th edn. ${ }^{b}$ Not available (not considered in the statistical calculations). 
Table 4. Multivariate analysis of the relationship between clinical pathological tumor features and survival with death-associated protein 1 (DAP1) expression.

\begin{tabular}{|c|c|c|c|c|c|c|}
\hline \multirow[t]{3}{*}{ Features } & \multicolumn{4}{|c|}{ Multivariate analysis } & \multirow{2}{*}{\multicolumn{2}{|c|}{$\begin{array}{c}\text { Cox proportional } \\
\text { Local disease-free survival }\end{array}$}} \\
\hline & \multicolumn{2}{|c|}{ Lymph node metastases } & \multicolumn{2}{|c|}{ Local disease relapse } & & \\
\hline & OR $(95 \% \mathrm{CI})$ & $P$ value & OR $(95 \% \mathrm{CI})$ & $P$ value & $\mathrm{HR}(95 \% \mathrm{CI})$ & $P$ value \\
\hline \multicolumn{7}{|c|}{ DAP1 expression } \\
\hline Low & 1 & & 1 & & 1 & \\
\hline High & $4.27(1.10-16.59)$ & 0.036 & $0.31(0.08-1.19)$ & 0.087 & $0.45(0.19-1.09)$ & 0.076 \\
\hline \multicolumn{7}{|c|}{ Tumor size $(\mathrm{T})^{\mathrm{a}}$} \\
\hline pT1, pT2 & 1 & & 1 & & 1 & \\
\hline pT3 & $1.98(0.36-10.90)$ & 0.432 & $7.93(1.13-55.89)$ & 0.038 & $2.47(0.86-7.12)$ & 0.094 \\
\hline pT4 & $5.53(1.37-22.32)$ & 0.016 & $1.46(0.36-5.86)$ & 0.597 & $1.96(0.68-5.64)$ & 0.210 \\
\hline \multicolumn{7}{|l|}{ Irradiated } \\
\hline No & - & - & 1 & & 1 & \\
\hline Yes & - & - & $0.29(0.08-1.09)$ & 0.068 & $0.43(0.17-1.09)$ & 0.077 \\
\hline
\end{tabular}

$\mathrm{OR}=$ odds ratio; $\mathrm{HR}=$ hazard ratio $\mathrm{CI}=$ confidence interval. ${ }^{\mathrm{a}} \mathrm{TNM}$ classification 7 th edn. Values were adjusted by multivariate analysis.

DAP1 expression levels were associated with local disease relapse $(\mathrm{P}=0.027$; Table 3). However, multivariate analysis did not confirm DAP1 as an independent marker of local disease relapse $(\mathrm{OR}=0.31,95 \% \mathrm{CI}=0.08-1.19$; Table 4$)$. DAP1 expression was not correlated with disease relapse and disease-specific death $(\mathrm{P}=0.083$ and $\mathrm{P}=0.747$, respectively; Table 3$)$.

Local disease-free survival was significantly correlated with DAP1 expression $(\mathrm{P}=$ 0.040 ). According to a 12 -month post-surgery follow-up, approximately $25 \%$ of patients with low DAP1 expression presented local disease relapse, whereas in the same period, $50 \%$ of patients with high expression relapsed for local disease (Figure 1A). However, multivariate analysis did not confirm DAP1 as an independent marker of local disease-free survival (HR $=0.45,95 \% \mathrm{CI}=0.19-1.09$; Table 4 ). In addition, DAP1 expression was not associated with disease-specific survival $(\mathrm{P}=0.546$; Figure $1 \mathrm{~B})$.

\section{DISCUSSION}

Autophagy is a well-conserved system for maintaining cellular homeostasis, and is activated by several factors, such as hypoxia, nutrient and growth factor starvation, oxidative stress, and DNA damage (Jung et al., 2010). It is also the mechanism by which apoptotic cells are removed (Levine et al., 2011; Oh and Lee, 2012).

DAP1-mediated dysregulation of autophagy has been associated with tumoral progression due to accumulation of damaged cells, altered proteins, mitochondrial damage, increased oxidative stress that causes DNA damage, and consequently tumor genetic changes (Karantza-Wadsworth et al., 2007; Eisenberg-Lerner and Kimchi, 2009; Yang et al., 2011).

In the present study, positive DAP1 expression was more frequently observed in tumor samples compared with normal tissue around the tumor. In a colorectal cancer study, DAP1 was underexpressed in tumor cells compared with normal adjacent cells (Jia et al., 2014). Autophagy has been associated with tumor suppression, with a strong influence on tumorigenesis. Therefore, higher DAP1 expression inhibits autophagy and helps tumor development (Mathew et al., 2007; White and DiPaola, 2009).

In addition, our results suggest that strong DAP1 expression is an independent risk 
factor for lymph node metastases development, increasing risk by over four times. There is a lack of data in the literature concerning the association of DAP1 expression and lymph node metastases. Autophagy inhibition may increase tumor cell life, augmenting genetic variation and leading to a worse prognosis, as described for breast cancer (Wazir et al., 2014) and colorectal cancer (Jia et al., 2014).
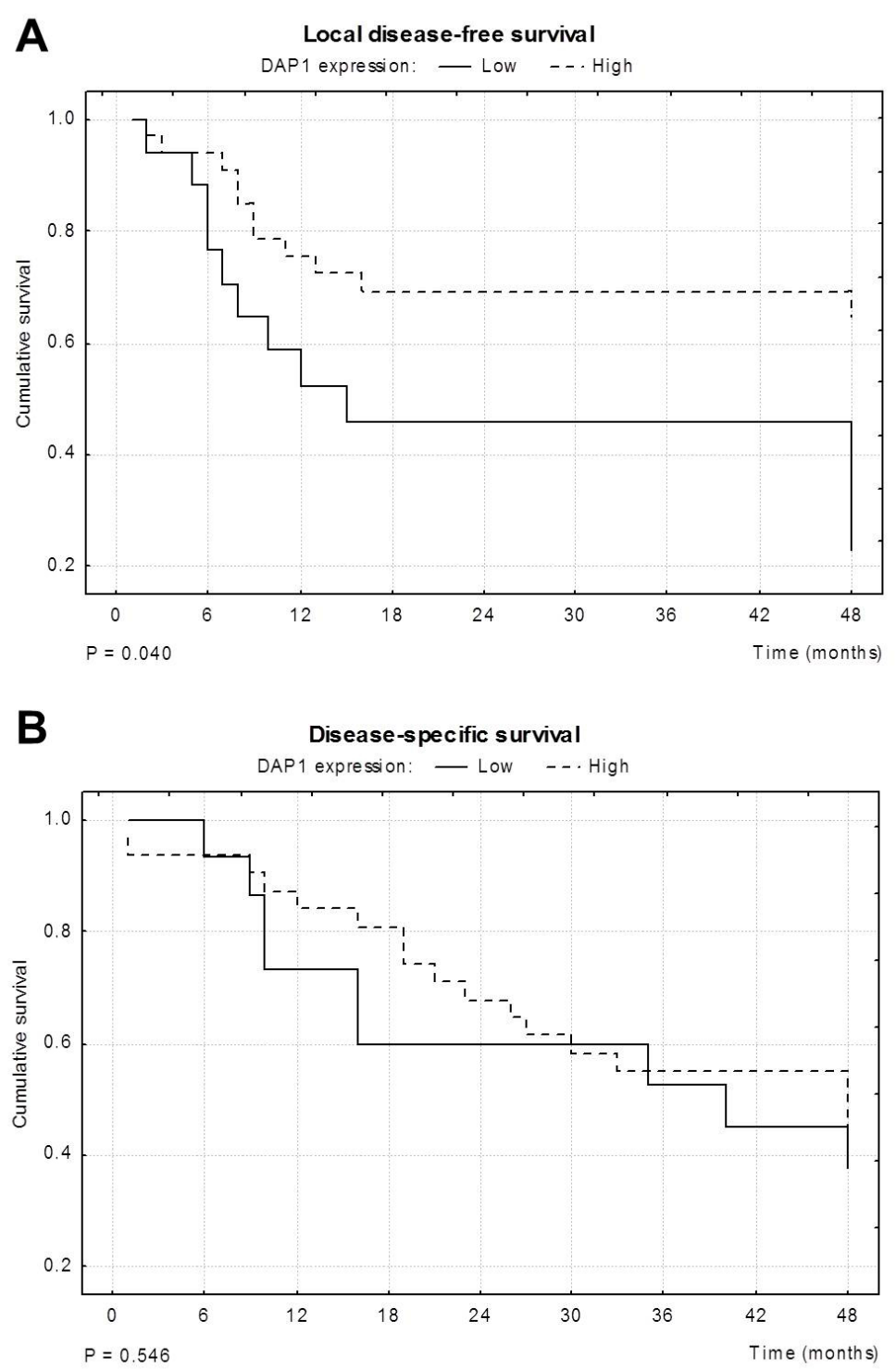

Figure 1. Survival plots. A. Local disease-free survival and B. disease-specific survival according to positive deathassociated protein 1 (DAP1) expression. 
Owing to its important role in autophagy, DAP1 has been associated with cell growth and death, as well as tumor development and prognosis (Koren et al., 2010).

In conclusion, our results suggest that DAP1 is a promising marker of lymph node metastases, helping clinicians select patients who are prone to metastasis and determine a more efficient therapy for them.

\section{Conflicts of interest}

The authors declare no conflict of interest.

\section{ACKNOWLEDGMENTS}

We are grateful to GENCAPO (Head and Neck Genome Project: http://www.gencapo. famerp.br/) team for the invaluable discussions that motivated the present study. The authors acknowledge the financial support from Fundação de Amparo à Pesquisa do Estado de São Paulo (FAPESP) and Fundação de Amparo à Pesquisa do Estado do Espírito Santo (FAPES), and the research fellowships from Conselho Nacional de Pesquisas (CNPq), and Coordenação de Aperfeiçoamento de Pessoal de Nível Superior (CAPES).

\section{REFERENCES}

Adrien J, Bertolus C, Gambotti L, Mallet A, et al. (2014). Why are head and neck squamous cell carcinoma diagnosed so late? Influence of health care disparities and socio-economic factors. Oral Oncol. 50: 90-97.

AJCC (American Joint Committee on Cancer) (2002). Cancer Staging Manual. 6th edn. (Greene FL, Page DL, Fleming ID, Fritz AG, et al., eds.). Springer, New York.

Cohen O, Inbal B, Kissil JL, Raveh T, et al. (1999). DAP-kinase participates in TNF-alpha- and Fas-induced apoptosis and its function requires the death domain. J. Cell Biol. 146: 141-148.

dos Santos M, Mercante AM, Louro ID, Gonçalves AJ, et al. (2012). HIF1-alpha expression predicts survival of patients with squamous cell carcinoma of the oral cavity. PLoS One 7: e45228.

Eisenberg-Lerner A and Kimchi A (2009). The paradox of autophagy and its implication in cancer etiology and therapy. Apoptosis 14: 376-391.

Forastiere A, Koch W, Trotti A and Sidransky D (2001). Head and neck cancer. N. Engl. J. Med. 345: 1890-1900.

Hedvat CV, Hegde A, Chaganti RS, Chen B, et al. (2002). Application of tissue microarray technology to the study of non-Hodgkin's and Hodgkin's lymphoma. Hum. Pathol. 33: 968-974.

Heroui AD, Danciu CE and Popescu CR (2013). Multiple Cancers of the Head and Neck. Maedica J. Clin. Med. 8: 80-85.

Hsu FD, Nielsen TO, Alkushi A, Dupuis B, et al. (2002). Tissue microarrays are an effective quality assurance tool for diagnostic immunohistochemistry. Mod. Pathol. 15: 1374-1380.

Jemal A, Siegel R, Ward E, Murray T, et al. (2007). Cancer statistics, 2007. CA Cancer J. Clin. 57: 43-66.

Jia Y, Ye L, Ji K, Toms AM, et al. (2014). Death associated protein 1 is correlated with the clinical outcome of patients with colorectal cancer and has a role in the regulation of cell death. Oncol. Rep. 31: 175-182.

Jung CH, Ro SH, Cao J, Otto NM, et al. (2010). mTOR regulation of autophagy. FEBS Lett. 584: 1287-1295.

Karantza-Wadsworth V, Patel S, Kravchuk O, Chen G, et al. (2007). Autophagy mitigates metabolic stress and genome damage in mammary tumorigenesis. Genes Dev. 21: 1621-1635.

Kondo Y, Kanzawa T, Sawaya R and Kondo S (2005). The role of autophagy in cancer development and response to therapy. Nat. Rev. Cancer 5: 726-734.

Koren I, Reem E and Kimchi A (2010). Autophagy gets a brake: DAP1, a novel mTOR substrate, is activated to suppress the autophagic process. Autophagy 6: 1179-1180.

Levine B, Mizushima N and Virgin HW (2011). Autophagy in immunity and inflammation. Nature 469: 323-335.

Mathew R, Kongara S, Beaudoin B, Karp CM, et al. (2007). Autophagy suppresses tumor progression by limiting chromosomal instability. Genes Dev. 21: 1367-1381. 
Mawrin C, Kirches E, Diete S, Wiedemann FR, et al. (2006). Analysis of a single nucleotide polymorphism in codon 388 of the FGFR4 gene in malignant gliomas. Cancer Lett. 239: 239-245.

McCarthy JF, Marx KA, Hoffman PE, Gee AG, et al. (2004). Applications of machine learning and high-dimensional visualization in cancer detection, diagnosis, and management. Ann. N. Y. Acad. Sci. 1020: 239-262.

Oh JE and Lee HK (2012). Modulation of pathogen recognition by autophagy. Front. Immunol. 3: 44.

Perez-Ordoñez B, Beauchemin M and Jordan RC (2006). Molecular biology of squamous cell carcinoma of the head and neck. J. Clin. Pathol. 59: 445-453.

Rimm DL, Camp RL, Charette LA, Olsen DA, et al. (2001). Amplification of tissue by construction of tissue microarrays. Exp. Mol. Pathol. 70: 255-264.

Severino P, Alvares AM, Michaluart P Jr, Okamoto OK, et al. (2008). Global gene expression profiling of oral cavity cancers suggests molecular heterogeneity within anatomic subsites. BMC Res. Notes 1: 113.

Stadler ME, Patel MR, Couch ME and Hayes DN (2008). Molecular biology of head and neck cancer: risks and pathways. Hematol. Oncol. Clin. North Am. 22: 1099-1124.

UICC (2009). TNM: Classification of Malignant Tumors. 7th edn. (Sobin LH, Gospodarowicz MK and Wittekind C, eds.). Wiley-Blackwell, Hoboken.

Wazir U, Khanzada ZS, Jiang WG, Sharma AK, et al. (2014). The interaction between DAP1 and autophagy in the context of human carcinogenesis. Anticancer Res. 34: 1-8.

White E and DiPaola RS (2009). The double-edged sword of autophagy modulation in cancer. Clin. Cancer Res. 15: 5308-5316.

Yang ZJ, Chee CE, Huang S and Sinicrope FA (2011). The role of autophagy in cancer: therapeutic implications. Mol. Cancer Ther. 10: 1533-1541. 